\title{
Economic load dispatch of wind-solar-thermal system using backtracking search algorithm
}

\author{
Nitin Tyagi ${ }^{1}$, Hari Mohan Dubey ${ }^{2}$, Manjaree Pandit ${ }^{3}$ \\ 1,2,3 Department of Electrical Engineering, Madhav Institute of Technology and Science, Gwalior, INDIA. \\ "Corresponding Author:harimohandubeymits@gmail.com e-mail: Tel +91-0751-2409348, +91-0751-2409380
}

\begin{abstract}
Due to rise in the price of fossil fuels and technical advances in the area of renewable energy, integrated systems became more popular now a day. However uncertain nature of wind, solar irradiation due to weather and climate change, integration of renewable power generation system complicates the ELD formulation. The paper presents optimum scheduling of integrated solarwind-thermal system using backtracking search algorithm (BSA). BSA is a novel population based stochastic search optimization technique, having simple structure and only one control parameter as population size. BSA has two new types of operator's as crossover and mutation for exploration and exploitation of search space of problem desired to be optimized and also satisfies all associated constraints of the objective function.
\end{abstract}

Keywords: BSA, Photovoltaic cell, Valve point loading effect, Probability density function.

DOI: http://dx.doi.org/10.4314/ijest.v8i4.3

\section{Introduction}

Economic load dispatch (ELD) problem is an essential optimization problem in electrical power system. The core aim of ELD problem is to minimize the operating fuel cost while satisfying all associated operating constraints (Wood et al., 1984). Finding optimal solution is very difficult as practical ELD problem is highly nonlinear due to presence of various practical operating constraints like valve point loading (VPL) effect, ramp rate limits(RRL) and prohibited operating zones(POZ)(Walter et al., 1993; Wang et al., 1993; Oreo et al., 1996). Conventional methods fail to solve problem with these types of operating constraints. To optimize these types of problems an intelligence scheduling of generating units is required and by this we can achieve minimum operating cost with higher reliability.

Recently, different nature inspired (NI) techniques that follow heuristic approaches have been proved to be effective with promising performance due to their ability to solve complicated problem specially related to power system. These include genetic algorithm (GA) (Walter et al., 1993; Oreo et al., 1996), evolutionary programming (EP) (Sinha et al., 2003), simulated annealing (SA) (Vishwakarma et al., 2013), differential evolution (DE) (Noman et al., 2008), particle swarm optimization (PSO) (Selvakumar et al., 2007; Chaturvedi et al., 2008; Park et al., 2010) etc. Recently novel NI techniques as well as improved version has been also proposed for solution of complex constrained ELD problem as bacterial foraging optimisation(BFO) (Panigrahi et al., 2008), biogeography-based optimization(BBO) (Bhattacharya et al., 2010), group search optimizer(GSO) (Dalvand et al., 2012 ), ant colony optimization(ACO) (Pothiya et al., 2010), cuckoo search algorithm(CSA)( Basu et al., 2013), krill herd algorithm(KHA)(Mandal et al., 2014) , chemical reaction optimization (CRO)( Roy et al., 2014), flower pollination Algorithm(FPA) (Dubey et al., 2015), gravitational search algorithm(GSA)(Udgir et al., 2013), hybrid PSO GSA(Dubey et al., 2014; Duman et al., 2015) , invasive weed optimization(IWO) ( Barisal et al., 2015) etc. Detail review of NI techniques for solution of ELD can be found in (Dubey et al, 2014).

Now a day's renewable energy resources and integrated power generation system has attracted much attention of researchers. Even though initial installation cost of renewable power generating system is higher, but the operating cost of solar and wind 
generating unit is significantly low. These are the two potential alternate energy resource attract much to match growing electric power demand of electricity as prices of limited fossil resources is increasing day by day. However unpredictable wind velocity of wind and weather dependent solar irradiation, unable to match time varying power demand as a result integrated power generation system creates new operational challenges for optimum generation scheduling. Here maintaining reliability is a big issue for the resulting integrated solar-wind-thermal system problem. Therefore ELD problem needs reformulation to include the operating constrains occurs due to uncertain nature of wind and weather dependent solar irradiation. In this area also from energy conservation point of view more researchers expressed their interest. Considering weather dependent and uncertainty, wind speed is mostly expressed as probability distribution function (pdf) )( Hetzer et al., 2008; Reddy et al., 2013; Zhu et al., 2014; Dubey et al., 2015 ). The wind integrated ELD modeling using pdf can be presented in ( Hetzer et al., 2008; Reddy et al., 2013; Zhu et al., 2014; Dubey et al., 2015 ) and modeling of solar-wind system is presented in(Karaki et al., 1999; Habib et al., 1999; Deshmukh et al., 2008; Reddy et al., 2015). Renewable power integration makes ELD model much complex due to additional constraints and required robust algorithm to solve these types of problems.

In this paper a novel optimization algorithm namely back tracking search (BSA) is applied to solve the ELD problems with/ without solar and wind power integration. BSA utilizes the principles of evolution and natural genetics where the population is updated by mutation, crossover and selection to generate the trial population.

\section{Problem formulation of ELD problem with solar and wind integration}

The ELD problem with wind integration has complex equality and inequality constraints associated with thermal, and wind power generating units. Due to zero fuel cost of solar power generation, the prime objective becomes minimization of fossil fuel cost of thermal units along with cost of wind power generating units $\left(F_{\text {Total }}\right)$. The objective function to be minimized as:

$$
F_{\text {Total }}=\sum_{i=1}^{m} F_{t h}\left(P_{i}\right)+\sum_{j=1}^{n} F_{w}\left(P_{w j}\right)
$$

The cost of thermal power generation with VPL effect can be written as:

$$
F_{t h}\left(P_{i}\right)=a_{i} P_{i}^{2}+b_{i} P_{i}+c_{i}+\left|d_{i} \sin \left(e_{i}\left(P_{i}^{\min }-P_{i}\right)\right)\right|(\$ / \mathrm{hr} .)
$$

The cost of thermal power generation with cubic function can be expressed as:

$$
F_{\text {th }}\left(P_{i}\right)=\left(a_{i} P_{i}^{3}+b_{i} P_{i}^{2}+c_{i} P_{i}+d_{i}\right)(\$ / \mathrm{hr} .)
$$

The cost of wind power output using wind power coefficient $\tau_{j}$ can be expressed as (Hetzer et al., 2008; Dubey et al., 2015):

$$
F_{w}\left(P_{w j}\right)=\sum_{j=1}^{n} \tau_{j} \times P_{w j}
$$

\subsection{Equality constraints}

$$
P_{D}=\sum_{i=1}^{m} P_{i}+P_{p v}+\sum_{j=1}^{n} P_{w j}
$$

\subsection{Inequality constraints}

Generation power should lie within minimum and maximum values.

$$
\begin{aligned}
& P_{i}^{\min } \leq P_{i} \leq P_{i}^{\max } \\
& P_{w j}{ }^{\min } \leq P_{i} \leq P_{w j}{ }^{\text {max }}
\end{aligned}
$$

\subsection{Modeling of wind power system}

The wind velocity is an arbitrary variable and wind power imparts a nonlinear connection to it. The wind speed information from different places is found to take after weibull distribution nearly and it is use for processing wind speed and wind power. pdf of wind velocity is expressed as (Hetzer et al., 2008; Reddy et al., 2013):

$$
p d f(u)=\frac{\beta}{\alpha}\left(\frac{v}{\alpha}\right)^{\beta-1} \exp \left[-\left(\frac{v}{\alpha}\right)^{\beta}\right]
$$

The wind power ( $W p)$ can be represented as a stochastic variable and calculated from wind speed as (Hetzer et al., 2008). 


$$
P_{w j}=\left\{\begin{array}{cc}
0 & \left(v<v_{c i} \quad \text { or } \quad v \geq v_{c o}\right. \\
P_{w j}^{R} & \left(v_{r} \leq v<v_{c o}\right) \\
\frac{\left(v-v_{i n}\right) P_{w j}^{R}}{v_{r}-v_{i n}} & \left(v_{c i} \leq v<v_{r}\right)
\end{array}\right.
$$

Whenever the wind speed is in between the $v_{r}$ and $v_{c}$, the power output of the wind farm is assumed to be a continuous variable, its pdf is given as (8). The total of all wind generator yields is taken as one random variable $P_{w j}$ and the $p d f$ is given by

$$
p d f\left(P_{w}\right)=\frac{\beta \gamma v_{i n}}{P_{w j}^{R} \alpha}\left[\frac{\left(1+\frac{\gamma P_{w j}}{P_{w j}^{R}}\right) v_{i n}}{\alpha}\right]^{\beta-1} \cdot \exp \left[-\left\{\frac{\left(1+\frac{\gamma P_{w j}}{P_{w j}^{R}}\right) v_{i n}}{\alpha}\right\}^{\beta}\right]
$$

$$
\text { Here } \gamma=\left(\left(\frac{v_{r}}{v_{c i}}\right)-1\right)
$$

To describe the condition that the available power is not ample to satisfy the total power demand, a probabilistic tolerance $\delta_{a}$ is chosen to model the uncertainty of wind power availability. In context to this the power balance constraint in (12) with wind and solar power is modified as expressed below.

$$
P_{r}\left(\sum_{j=1}^{n} P_{w}^{j}+\sum_{i=1}^{m} P_{i}+P_{p v} \leq\left(P_{D}\right) \leq \delta_{a}\right.
$$

A smaller value of $\delta_{a}$ decreases the risk of not enough wind power and increases the thermal generation to ensure the good reserve capacity.

\subsection{Modeling for photovoltaic (PV) system}

Power output PV generator mainly depends on solar radiation and temperature. The hourly power output of PV generator can be calculated as (Deshmukh et.al., 2008, Habib et al.,1999) :

$$
P_{s}=I_{T} \eta A_{p v}
$$

For PV system average solar radiation $\left(I_{T}\right)$ for an inclined surface can be calculated as (Duffie et al.,1991) :

$$
I_{T}=I_{a} R_{a}+I_{b} R_{b}+\left(I_{a}+I_{b}\right) R_{r}
$$

System efficiency $(\eta)$ is represented as (Habib et al.,1999):

$$
\eta=\eta_{m} \eta_{p c e} P_{f}
$$

Where, $\eta_{m}=\eta_{r e}\left[1-\beta\left(T_{k}-T_{r e}\right)\right]$ 


\section{Backtracking search algorithm}

BSA is a metaheuristic technique based on the principles of evolution and natural genetics where the population is updated by mutation, crossover and selection to generate the trial population(Civicioglu et al.,2013). The five processes used here are initialization, selection-I, mutation, crossover and selection-II. The mutation and crossover operations in BSA are relatively different from that of GA and DE and are found to produce better population diversity. BSA is a double population algorithm which makes use of random past experiences stored in its memory. Most NI techniques make use of the better or best individuals for generating new solutions but BSA employs the current and previous iteration populations, non-uniform crossover, a random mutation strategy having only one direction individual for each solution and a novel boundary control mechanism. The magnitude of mutation is controlled by a random mutation factor drawn from the normal distribution which randomly controls exploration/exploitation depending on larger/smaller value of the mutation factor. There is only one control parameter mixrate which controls the number of elements of individuals which are mutated in each iteration. BSA has various principle steps as initialization, selection-I, mutation, crossover and selection-II and are described as below. Figure 2 shows the flow chart of BSA.

\subsection{Initialization}

In this process a set of population is randomly generated within the limits of upper bound (ub) and lower bound (lb) as:

$$
\text { pop }=l b+\text { rand } *(u b-l b)
$$

rand is any random number between 0 and 1 .

\subsection{Selection-I}

Here a set of historical population is generated. The process of generation of historicalpop is same as the pop.

$$
\text { historical pop }=l b+\text { rand } *(u b-l b)
$$

Then each element of historical population is updated through a simple reasoning as below:

$$
\text { if } \quad i<j, \quad \text { historical pop }=\text { pop } \quad \text { end } \quad i, j \in(0,1)
$$

The advantage of generating historical pop is that, it is stored in BSA as a memory and historical pop is not changed until it's get a better fitness value.

After that a permute process is used to change the order of individuals of historicalpop :

historical pop $=$ historical pop (randperm $($ popsize $))$

\subsection{Mutation}

In mutation process mutants i.e. trial population matrix are generated as:

$$
\text { mutant }=\text { pop }+M *(\text { historical pop }- \text { pop })
$$

Where $\mathrm{M}$ is taken $\left(3^{*} r n d n\right)$ and it controls the amplitude of search- direction matrix (historicalpop-pop) and it is based upon standard Brownian walk. Mutants take some advantage from grown experienced or previous generation due to involvement of historical population.

\subsection{Crossover}

As an initial form of trial population is generated as per (21) and here final form of trial population is generated. There are two algorithms inside crossover process, first is for generation of integer valued matrix $\left(B_{\text {map }}\right)$ and second is for mixrate that controls the number of elements and they will further mutate by (mixrate * rand $\left.{ }^{*} D\right)$. Here $D$ is the dimension of the problem.

\subsection{Selection-II}

It is the final stage of BSA, here all the population sets are put together and compared to get a better fitness value of population. If in selection-II process the updated values have better fitness then the global minimum value of individual of population obtained so far. Then it is updated to global minimizer.

The pseudo code depicted in Figure 1 shows the process applied as selection I, Mutation and crossover in BSA algorithm for optimization. 


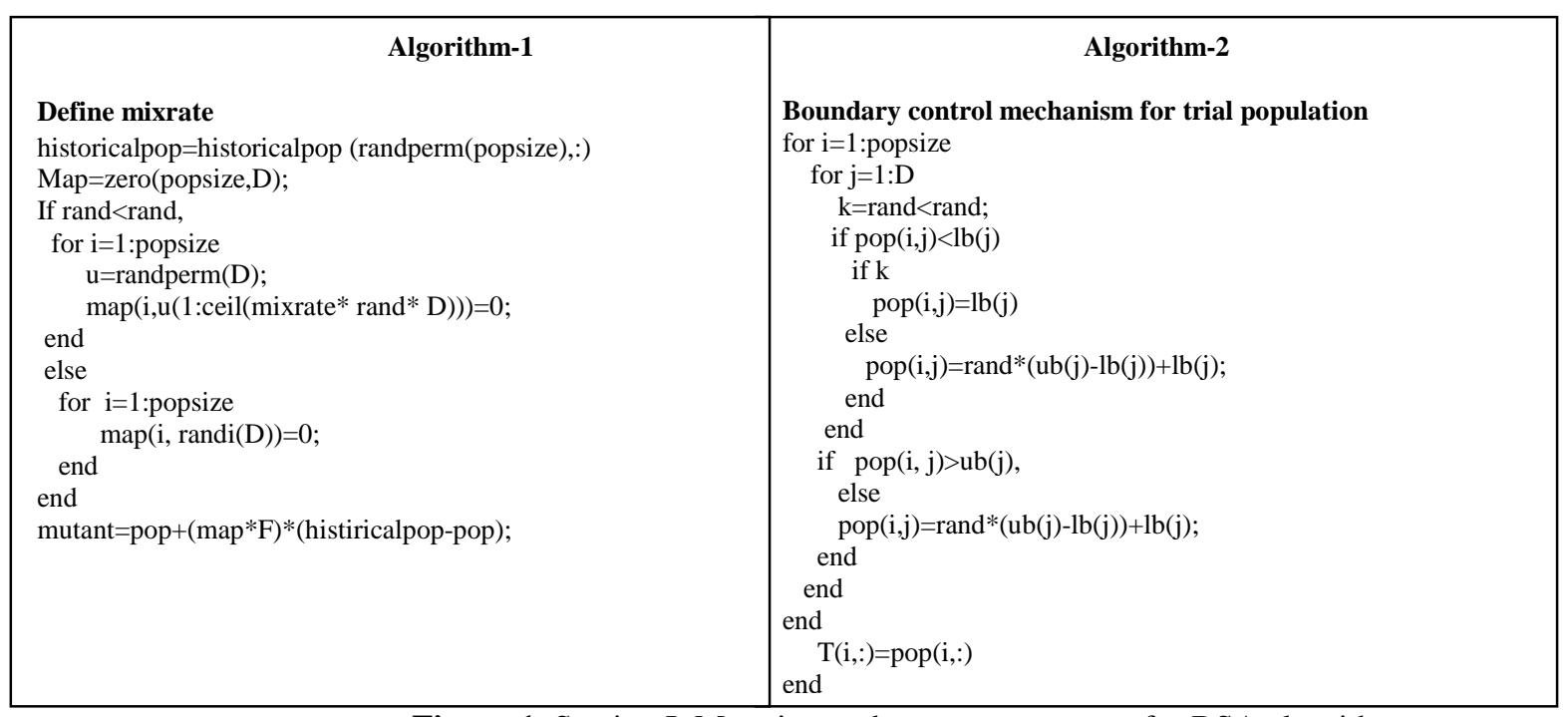

Figure 1. Section I, Mutation and crossover process for BSA algorithm

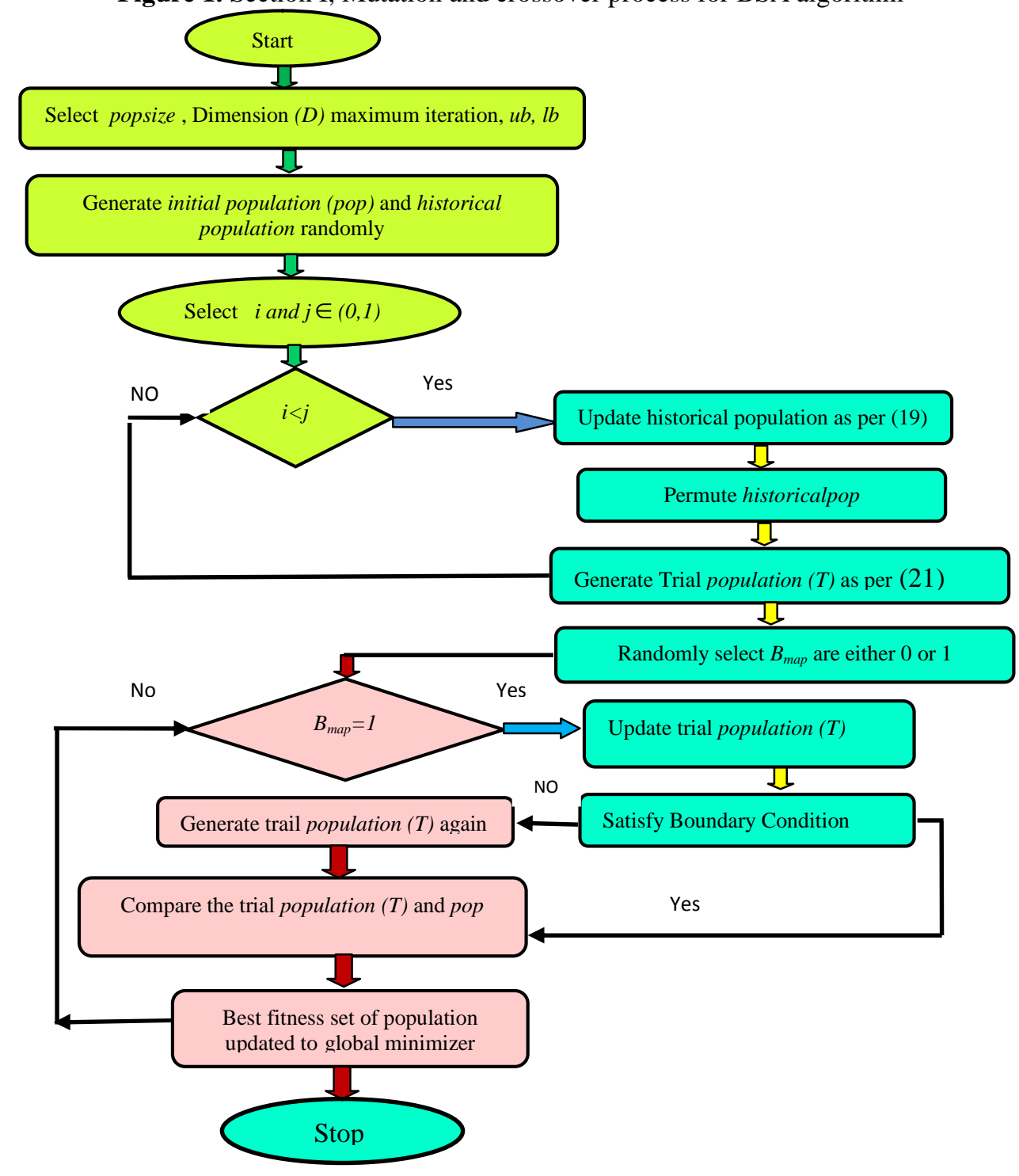

Figure 2. Flow chart of Backtraking search algorithm 


\section{Implementation of BSA for solar-wind-thermal scheduling}

Step-1: Each individual set of population matrix is Initialized as per (22) generated within the limits of maximum and minimum power dispatched

$$
\text { pop }=P_{i}^{\min }+\operatorname{rand}(N, D) *\left(P_{i}^{\max }-P_{i}^{\min }\right)
$$

Step-2: Evaluate the objective function for each set of population generated by (22) with the satisfaction of all constraints (5)-(10).

Step-3: Based on values of objective function identify the best population set which gives minimum values of (1), and keep it unchanged after each iteration without making any modification in it.

Step-4: Now historical population is initialized the using (18).Compute the objective function as per the historical population after that each set of historical population is updated as per (19) for each iteration. After making new set of historical population each set of power dispatched is shuffled as per (20).

Step-5: Initial position of mutant matrix is produced using (21).

Step-6: Trial population set (T) is generated in this step. The algorithm-1 defines the mixrate and algorithm- 2 defines the boundary control mechanism. Update the values of $T$ is applicable to individuals of generated matrix. Compute the objective function for $T$.

Step-7: For population (рор) set and trial population $(T)$ set the values of objective function is compared. If the set of population has better fitness than the global minimum value then this new set of population is updated to global minimizer.

Step-8: Iteration process is terminated here as if current iteration is greater than or equal to maximum iteration. Store the best power output in an array otherwise repeat step-1 to step-7 in that order.

\section{Results and discussion}

To demonstrate the efficiency of BSA, it is applied and test on three types of test cases, namely optimal scheduling of thermal system, optimal scheduling of solar-thermal system and optimal scheduling of solar-wind-thermal system. code of all test cases is developed and implemented in MATLAB 9 and programs are executed on $2.10 \mathrm{GHz}$ Intel Pentium Processor with 1.0 GB RAM.

\subsection{Description of Test cases}

Test Case-1:

In this test case standard 13 generating unit with valve point loading effect (Sinha N. et al., 2003).

Load demand is set at 2520MW and transmission loss is not considered here.

Test Case-2:

In this test case has 26 generating units with cubic fuel cost characteristic (Chandram et al., 2011). The power demand is set at 2900MW and transmission losses are not considered here.

Test Case-3:

It is a composite solar-thermal system having 26 thermal generating units similar to test case 2 and a solar plant of maximum rating $50 \mathrm{MW}$. The data for radiation and average ambient temperature is adopted as per (Solar Radiation Hand Book, et al.,2008)

for city Delhi (India). The other data for PV generator are set at $P_{f}=0.9, A_{p v}=90163.04 \mathrm{~m}^{2}, \beta=-4.7 \mathrm{e}-3, \eta_{r e}=0.105, \eta_{p c e}=0.9$ and $T_{r e}$ $=25^{\circ} \mathrm{C}$.

Test Case-4:

It is an integrated wind-solar-thermal system. Here all power generating unit data are considered similar to test case 3 along with an additional wind farm. The cost coefficient for wind farm considered as $k r=1, k p=5$, rated power output $155 \mathrm{MW}$. The other constants are set at $v_{c i}=5, v_{c o}=45$ and $v_{r}=15$. The shape and scale factor are considered as 1 and 15 respectively. The whole network adopted for simulation analysis in this test case is shown in Figure 3. 
Wind power Plant

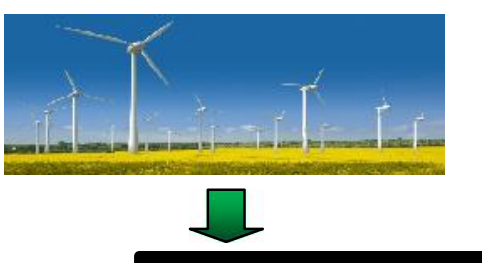

Solar Power Plant
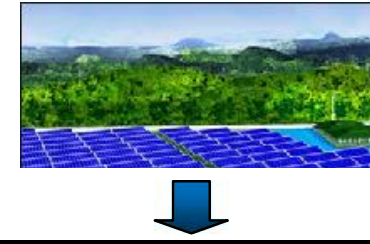

\section{Power Demand}

Figure 3. Wind-solar- Thermal system

\subsection{Selection of Parameters}

BSA belongs to the family of stochastic method; it requires optimal selection of tuning parameter to get global optima solution. In order to explore best tuning parameter BSA, it is applied and tested on test case 1 having 13 power generating unit system with non convex fuel cost characteristic. As BSA have only one control parameter as pop size (NP), twenty-five independent run were conducted with different value of NP. The statistical results obtained by simulation are tabulated in Table.1. Here it is observed that optimum operating cost is obtained with $\mathrm{NP}=100$ with comparatively low standard deviation (SD) of $\mathbf{0 . 7 5 0}$, therefore selected for simulation analysis.

Table 1. Effect of pop size (NP)

\begin{tabular}{|l|l|l|l|l|l|}
\hline Pop Size $(\mathrm{NP})$ & Min cost $(\$ / \mathrm{h})$ & Max cost $(\$ / \mathrm{h})$ & Ave cost $(\$ / \mathrm{h})$ & S.D & CPU $(\mathrm{s})$ \\
\hline 50 & 24165.2809 & 24166.7871 & 24165.9115 & 0.574 & $\mathbf{4 . 0 7}$ \\
\hline 100 & $\mathbf{2 4 1 6 4 . 0 5 2 4}$ & $\mathbf{2 4 1 6 6 . 5 8 3 1}$ & $\mathbf{2 4 1 6 4 . 2 9 4 2}$ & $\mathbf{0 . 7 5 0}$ & $\mathbf{5 . 1 2}$ \\
\hline 150 & 24164.7986 & 24165.9506 & 24165.2273 & 0.4261 & $\mathbf{7 . 6 5}$ \\
\hline 200 & 24164.5755 & 24165.4754 & 24164.9175 & 0.3068 & $\mathbf{1 1 . 3 6}$ \\
\hline
\end{tabular}

\subsection{Optimal dispatch solution Comparison of results}

As test case 1 is highly nonlinear multi-model problem due to valve point loading effect, and it is quite difficult to get global best solution. Here the optimum cost obtained by BSA is $24164.0524 \$ / \mathrm{hr}$, which is found to be better than recent reported method as Genetic algorithm (GA) (Noman et al., 2008), Differential evolution (DE) (Noman et al., 2008), Hybrid Chemical reaction Optimization(HCRO) (Roy et al., 2014), Chemical Reaction Optimization (CRO) (Roy et al., 2014), Iteration PSO with time varying acceleration coefficients (IPSO_TVAC) (Ivatloo et al., 2012) and Simulated annealing (SA) (Vishwakarma et al., 2012). The Optimal dispatch solution obtained by BSA and statistical comparison of results are presented in table 2 and table 3 respectively. The convergence characteristic obtained by BSA for test case 1 is plotted in Figure 4.

For test case 2, which is comparatively a large system and have cubic fuel cost characteristic, the optimum cost obtained by BSA over twenty-five repeated trails is $43436.5297(\$ / \mathrm{hr})$. Here also the results obtained by BSA are found to be comparable with Hybrid PSO-GSA (Dubey et al., 2014) and Equal Embedded Algorithm (EEA) (Chandram et al., 2011) as depicted in Table 4.

Similarly for renewable power integration as in test case 3, the best cost solution obtained by BSA is 42250.8926 ( $\$ / \mathrm{hr})$, where as for wind-solar-thermal test case 4 it is $40608.8435(\$ / \mathrm{hr})$. Their full dispatch solutions are presented in Table 5. Here it observed that total operating cost reduced by approximately $3 \%$ by solar integration and by $6.5 \%$ by integration of both wind and solar system as compared to thermal system with cubic fuel cost characteristic as described in test case 2 . The smooth and stable convergence characteristic obtained by BSA for thermal system (test case 2), solar thermal system (test case 3) and, integrated wind-solar- thermal system (test case 4) is plotted in Figure 5.

Table 2. Optimal Power Dispatch for 13 unit system test case 1

\begin{tabular}{|l|l|l|l|l|l|l|l|}
\hline Unit & GA** & DE** & CRO** & HCRO** & IPSO_TVAC** & SA** & BSA \\
\hline $\mathrm{P}_{1}(\mathrm{MW})$ & 628.32 & 628.3185 & 628.3149 & 628.3185 & 628.319 & 628.3185 & 628.3185 \\
\hline $\mathrm{P}_{2}(\mathrm{MW})$ & 356.49 & 299.1993 & 299.2010 & 299.1993 & 299.199 & 299.1993 & 299.1993 \\
\hline $\mathrm{P}_{3}(\mathrm{MW})$ & 359.43 & 299.1993 & 294.9875 & 294.9957 & 295.878 & 299.1993 & 294.4848 \\
\hline $\mathrm{P}_{4}(\mathrm{MW})$ & 159.73 & 159.7331 & 159.7100 & 159.7331 & 159.265 & 159.7331 & 159.7331 \\
\hline
\end{tabular}


Table 2 (cont'd). Optimal Power Dispatch for 13 unit system test case 1

\begin{tabular}{|l|l|l|l|l|l|l|l|}
\hline Unit & GA** & DE** & CRO** & HCRO** & IPSO_TVAC** & SA** & BSA \\
\hline $\mathrm{P}_{5}(\mathrm{MW})$ & 109.86 & 159.7331 & 159.7335 & 159.7331 & 159.733 & 159.7331 & 159.7331 \\
\hline $\mathrm{P}_{6}(\mathrm{MW})$ & 159.73 & 159.7331 & 159.7330 & 159.7331 & 159.733 & 159.7331 & 159.7331 \\
\hline $\mathrm{P}_{7}(\mathrm{MW})$ & 159.63 & 159.7331 & 159.7332 & 159.7331 & 159.733 & 159.7331 & 159.7330 \\
\hline $\mathrm{P}_{8}(\mathrm{MW})$ & 159.73 & 159.7331 & 159.7330 & 159.7331 & 159.733 & 159.7331 & 159.7331 \\
\hline $\mathrm{P}_{9}(\mathrm{MW})$ & 159.73 & 159.7331 & 159.7332 & 159.7331 & 159.733 & 159.7331 & 159.7331 \\
\hline $\mathrm{P}_{10}(\mathrm{MW})$ & 77.31 & 77.3999 & 77.3631 & 77.3999 & 77.363 & 77.3999 & 77.3999 \\
\hline $\mathrm{P}_{11}(\mathrm{MW})$ & 75.00 & 77.3999 & 77.2999 & 77.3999 & 77.397 & 77.3999 & 77.3999 \\
\hline $\mathrm{P}_{12}(\mathrm{MW})$ & 60.00 & 92.3999 & 92.4154 & 92.3999 & 92.397 & 87.6845 & 92.3997 \\
\hline $\mathrm{P}_{13}(\mathrm{MW})$ & 55.00 & 87.6845 & 92.0423 & 91.8882 & 91.517 & 92.3999 & 92.3997 \\
\hline Total $\operatorname{cost}(\$ / \mathrm{h})$ & 24398.23 & 24169.9177 & $24,165.1664$ & $24,164.8260$ & $24,166.8$ & 24169.9176 & $\mathbf{2 4 1 6 4 . 0 5 2 4}$ \\
\hline
\end{tabular}

Table 3. Statistical results for 13 unit system test case 1

\begin{tabular}{|l|l|l|l|l|l|}
\hline Methods & CRO** & HCRO** & IPSO_TVAC** & SA** & BSA \\
\hline Min cost $(\$ / \mathrm{h})$ & $24,165.1664$ & $24,164.8260$ & $24,166.8$ & 24169.9176 & 24164.0524 \\
\hline Max cost $(\$ / \mathrm{h})$ & $24,169.3642$ & $24,165.3402$ & $24,169.41$ & N.A & 24166.5831 \\
\hline Average cost $(\$ / \mathrm{h})$ & $24,166.9355$ & $24,164.9837$ & $24,167.37$ & N.A & 24164.2942 \\
\hline S.D & 0.94 & 0.93 & N.A & N.A & 0.75 \\
\hline Ave CPU time(sec) & 5.56 & 5.04 & N.A & N.A & 5.12 \\
\hline
\end{tabular}

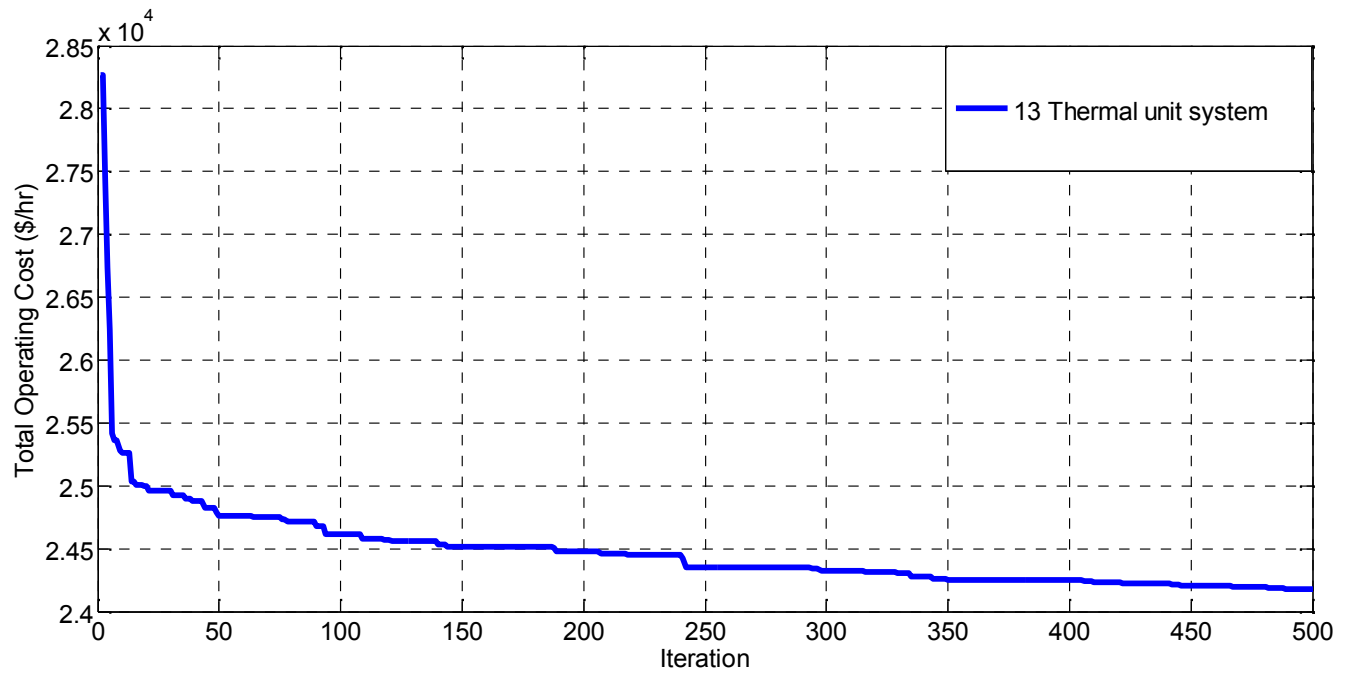

Figure 4. Convergence characteristic of non convex 13 unit system, power demand=2520MW

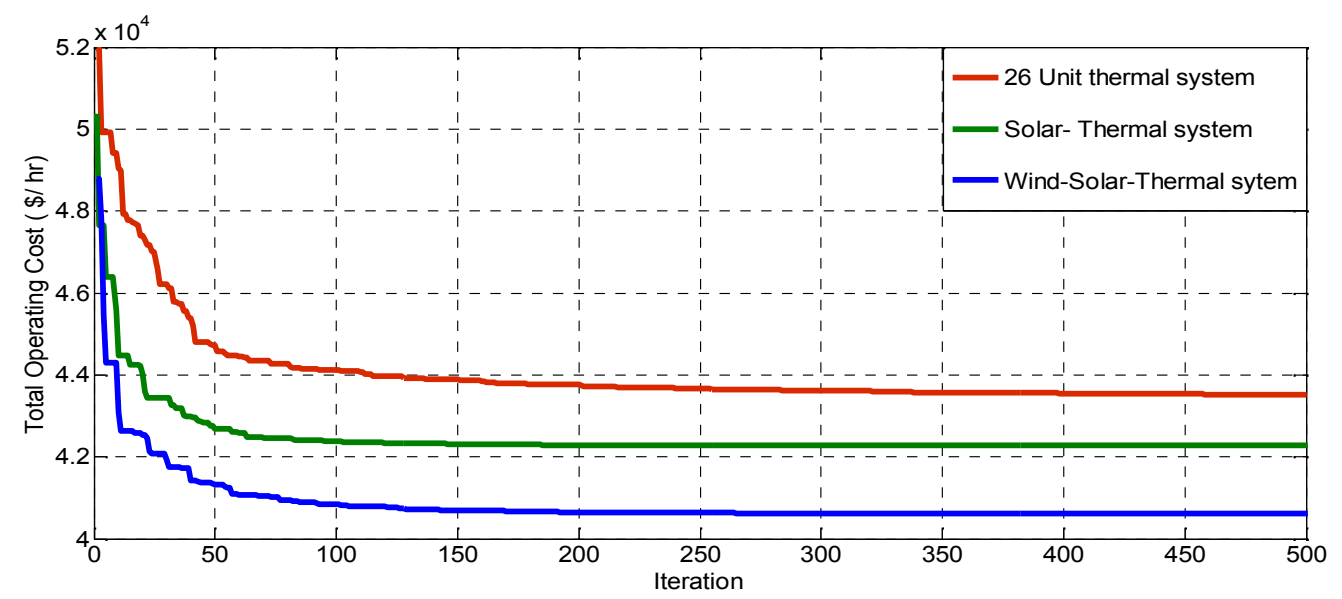

Figure 5. Convergence characteristic of 26 unit system, power demand=2900MW 
Table 4. Optimal Power Dispatch for 26 unit system

\begin{tabular}{|c|c|c|c|c|c|c|c|}
\hline Unit & EEA* & TVPSOGSA** & BSA & Unit & EEA** & TVPSOGSA** & BSA \\
\hline $\mathrm{P}_{1}(\mathrm{MW})$ & 2.40000 & 2.40000 & 2.40001 & $\mathrm{P}_{14}(\mathrm{MW})$ & 100.00000 & 100.00000 & 100.00000 \\
\hline $\mathrm{P}_{2}(\mathrm{MW})$ & 2.40000 & 2.40000 & 2.40002 & $\mathrm{P}_{15}(\mathrm{MW})$ & 100.00000 & 100.00000 & 100.00000 \\
\hline $\mathrm{P}_{3}(\mathrm{MW})$ & 2.40000 & 2.40000 & 2.40000 & $\mathrm{P}_{16}(\mathrm{MW})$ & 100.00000 & 100.00000 & 100.00000 \\
\hline $\mathrm{P}_{4}(\mathrm{MW})$ & 2.40000 & 2.40000 & 2.40004 & $\mathrm{P}_{17}(\mathrm{MW})$ & 155.00000 & 155.00000 & 155.00000 \\
\hline $\mathrm{P}_{5}(\mathrm{MW})$ & 2.40000 & 2.40000 & 2.40001 & $\mathrm{P}_{18}(\mathrm{MW})$ & 155.00000 & 155.00000 & 155.00000 \\
\hline $\mathrm{P}_{6}(\mathrm{MW})$ & 4.00000 & 4.000000 & 4.00003 & $\mathrm{P}_{19}(\mathrm{MW})$ & 155.00000 & 155.00000 & 155.00000 \\
\hline $\mathrm{P}_{7}(\mathrm{MW})$ & 4.00000 & 4.00000 & 4.00003 & $\mathrm{P}_{20}(\mathrm{MW})$ & 155.00000 & 155.00000 & 155.00000 \\
\hline $\mathrm{P}_{8}(\mathrm{MW})$ & 4.00000 & 4.00000 & 4.00004 & $\mathrm{P}_{21}(\mathrm{MW})$ & 190.99000 & 187.86800 & 190.99900 \\
\hline $\mathrm{P}_{9}(\mathrm{MW})$ & 4.00000 & 4.00000 & 4.00002 & $\mathrm{P}_{22}(\mathrm{MW})$ & 166.00000 & 165.09440 & 166.00000 \\
\hline $\mathrm{P}_{10}(\mathrm{MW})$ & 76.000000 & 76.00000 & 76.00000 & $\mathrm{P}_{23}(\mathrm{MW})$ & 141.00000 & 145.03760 & 141.00100 \\
\hline $\mathrm{P}_{11}(\mathrm{MW})$ & 76.00000 & 76.00000 & 76.00000 & $\mathrm{P}_{24}(\mathrm{MW})$ & 350.00000 & 350.00000 & 350.00000 \\
\hline $\mathrm{P}_{12}(\mathrm{MW})$ & 76.00000 & 76.00000 & 76.00000 & $\mathrm{P}_{25}(\mathrm{MW})$ & 400.00000 & 400.00000 & 400.00000 \\
\hline $\mathrm{P}_{13}(\mathrm{MW})$ & 76.00000 & 76.00000 & 76.00000 & $\mathrm{P}_{26}(\mathrm{MW})$ & 400.00000 & 400.00000 & 400.00000 \\
\hline \multicolumn{5}{|c|}{ Total $\operatorname{cost}(\$ / h)$} & 43436.5 & 43436.58355 & 43436.5297 \\
\hline
\end{tabular}

Table 5. Optimal power dispatch solution for renewable integrated system obtained by BSA

(Test case 3 and Test case 4)

\begin{tabular}{|c|c|c|}
\hline Unit & Test case 3:Solar Thermal system & Test case 4:wind-Solar- Thermal system \\
\hline $\mathrm{P}_{1}(\mathrm{MW})$ & 2.40195 & 12.0000 \\
\hline $\mathrm{P}_{2}(\mathrm{MW})$ & 2.40296 & 2.4014 \\
\hline $\mathrm{P}_{3}(\mathrm{MW})$ & 2.40235 & 2.4118 \\
\hline $\mathrm{P}_{4}(\mathrm{MW})$ & 2.40286 & 2.4012 \\
\hline $\mathrm{P}_{5}(\mathrm{MW})$ & 2.40033 & 2.4059 \\
\hline $\mathrm{P}_{6}(\mathrm{MW})$ & 4.00003 & 4.0006 \\
\hline $\mathrm{P}_{7}(\mathrm{MW})$ & 4.00003 & 4.0000 \\
\hline $\mathrm{P}_{8}(\mathrm{MW})$ & 4.00005 & 4.0008 \\
\hline $\mathrm{P}_{9}(\mathrm{MW})$ & 4.00005 & 4.0000 \\
\hline $\mathrm{P}_{10}(\mathrm{MW})$ & 75.9999 & 76.0000 \\
\hline $\mathrm{P}_{11}(\mathrm{MW})$ & 75.9999 & 75.9999 \\
\hline $\mathrm{P}_{12}(\mathrm{MW})$ & 75.9999 & 76.0000 \\
\hline $\mathrm{P}_{13}(\mathrm{MW})$ & 75.9999 & 76.0000 \\
\hline $\mathrm{P}_{14}(\mathrm{MW})$ & 100.0000 & 99.9988 \\
\hline $\mathrm{P}_{15}(\mathrm{MW})$ & 99.9999 & 99.9984 \\
\hline $\mathrm{P}_{16}(\mathrm{MW})$ & 99.9998 & 99.9979 \\
\hline $\mathrm{P}_{17}(\mathrm{MW})$ & 155.0000 & 155.0000 \\
\hline $\mathrm{P}_{18}(\mathrm{MW})$ & 155.0000 & 154.9998 \\
\hline $\mathrm{P}_{19}(\mathrm{MW})$ & 155.0000 & 154.9988 \\
\hline $\mathrm{P}_{20}(\mathrm{MW})$ & 155.0000 & 155.0000 \\
\hline $\mathrm{P}_{21}(\mathrm{MW})$ & 175.1190 & 119.1194 \\
\hline $\mathrm{P}_{22}(\mathrm{MW})$ & 148.2370 & 93.2265 \\
\hline $\mathrm{P}_{23}(\mathrm{MW})$ & 124.6710 & 71.0914 \\
\hline $\mathrm{P}_{24}(\mathrm{MW})$ & 350.0000 & 349.9996 \\
\hline $\mathrm{P}_{25}(\mathrm{MW})$ & 400.0000 & 399.9985 \\
\hline $\mathrm{P}_{26}(\mathrm{MW})$ & 400.0000 & 399.9980 \\
\hline $\mathrm{P}_{\text {solar }}(\mathrm{MW})$ & 49.9636 & 49.9521 \\
\hline $\mathrm{P}_{\text {wind }}(\mathrm{MW})$ & NA & 154.9992 \\
\hline Total thermal $\operatorname{cost}(\$ / \mathrm{h})$ & 42250.8926 & 40283.6778 \\
\hline Wind over estimation $\operatorname{cost}(\$ / \mathrm{hr})$ & NA & 325.1642 \\
\hline Wind under estimation $\operatorname{cost}(\$ / \mathrm{hr})$ & NA & 0.0015 \\
\hline Total operating $\operatorname{cost}(\$ / \mathrm{hr})$ & 42250.8926 & 40608.8435 \\
\hline
\end{tabular}




\subsection{Computational efficiency and robustness}

The computation time for BSA over 25 independent trials is used to authenticate the computational efficiency of applied approach. Form table 3 it is evident that standard deviation for test case 1 is found to be low which approves that BSA is computationally efficient .Also as per statistical results in terms of minimum, maximum, average cost, S.D and average CPU time in table 3 confirms the superiority and robustness of BSA for complex constrained optimization problems related to power system.

The average CPU time associated with different test cases under investigation are depicted in figure 6.which is found to be obvious as per complexity and dimension of test cases.

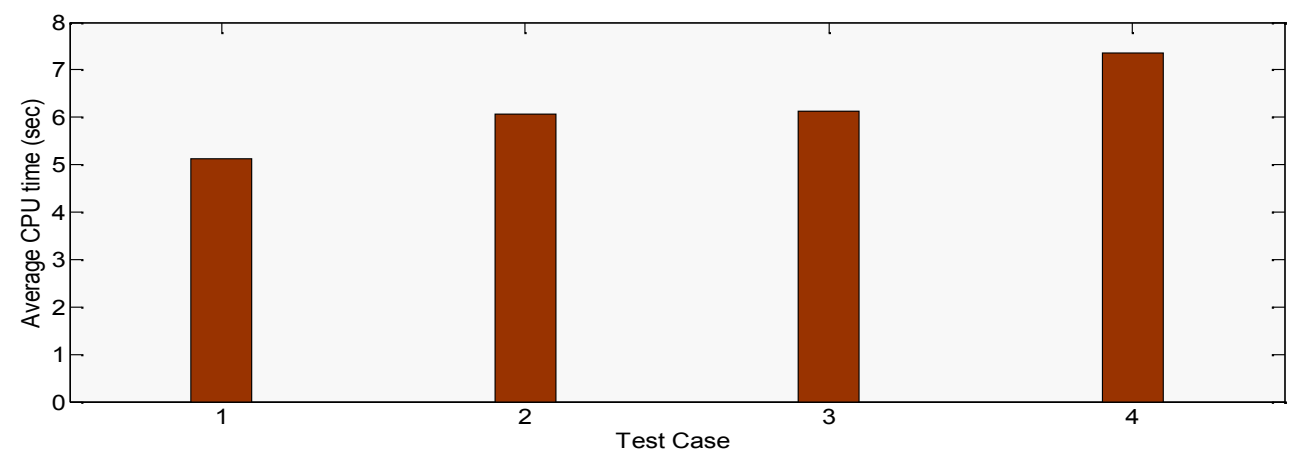

Figure 6. Average CPU time for different test cases

\section{Conclusion}

The paper presents a novel optimization technique BSA to solve ELD problem with / without integration of solar power. Wind power is model by pdf where as solar photo voltaic system is model by deterministic approach. As BSA is a double population algorithm employs the current and previous iteration populations, non-uniform crossover, a random mutation strategy having only one direction individual for each solution and an efficient boundary control mechanism which helps to attain global best solution. As a results simulation results obtained by BSA is found to be significantly better than individual performances of GA, DE, CRO, IPSO_TVAC, SA and TVPSOGSA. All operating constraints are satisfied as well as BSA compute best dispatch solution in efficient manner irrespective of dimension and complexity of test cases. It can be easily applied and extended for solution of large scale optimization problem related to power system operation and control.

\section{Nomenclature}

$\begin{array}{ll}F_{t h}\left(P_{i}\right) & \text { Cost associated with power generation of } i^{\text {th }} \text { thermal unit } \\ F_{w}\left(P_{w j}\right) & \text { Cost associated with power generation of } j^{\text {th }} \text { wind farm } \\ F_{\text {Total }} & \text { Total operating cost of power generation } \\ a_{i,}, b_{i}, c_{i}, d_{i} \& e_{i} & \text { Cost coefficients of } i^{\text {th }} \text { generating unit } \\ m & \text { number of thermal power units } \\ n & \text { number of wind farm } \\ P_{D} & \text { Total Power Demand } \\ P_{i}^{\min }, P_{i}^{\max } & \text { Minimum and maximum power output limit of } i^{\text {th }} \quad \text { thermal generating unit } \\ P_{w j}^{\min }, P_{w j}^{\max } & \text { Minimum and maximum power output limit of } j^{\text {th }} \text { wind farm } \\ p d f & \text { Probability density function } \\ a, \beta & \text { shape and scale factor } \\ v_{r}, v_{c i} \text { and } v_{c o} & \text { rated wind speed, cut-in speed and cut-out speed } \\ I_{T} & \text { Average solar radiation incident on PV surface } \\ I_{a} \text { and } I_{b} & \text { normal and diffuse solar radiations } \\ R_{a}, R_{b} \text { and } R_{r} & \text { tilt factor for normal, diffused and refracted surface } \\ A_{p v} & \text { Area of Solar Modules } \\ P_{s} & \text { Average power output of PV generator } \\ \eta & \text { System efficiency } \\ \eta_{p c e} & \text { Power conditioning efficiency } \\ P_{f} & \text { Packing factor } \\ \eta_{m} & \text { Module efficiency }\end{array}$




$\begin{array}{ll}\eta_{r e} & \text { Reference module efficiency } \\ \beta & \text { Array efficiency temperature coefficient } \\ T_{k} & \text { Average cell temperature } \\ T_{r e} & \text { Reference temperature for cell efficiency } \\ * * & \text { Result from references } \\ N I & \text { Nature Inspired } \\ N A & \text { Not available in literature } \\ S . D & \text { Standard Deviation }\end{array}$

\section{Acknowledgments}

Authors are thankful to the Director, Madhav Institute of Technology \& Science, Gwalior (M.P) India for providing support and facilities to carry out this research work.

\section{References}

Barisal A.K.and Prusty R.C., 2015. Large scale economic dispatch of power systems using oppositional invasive weed optimization. Appl. Soft Compt., Vol.29, pp. 122-137.

Basu M,and Chowdhury A., 2013. Cuckoo search algorithm for economic dispatch. Energy, Vol.60, pp.99-108.

Bhattacharya A and Chattopadhyay PK., 2010. Biogeography-based optimization for different economic load dispatch problems. IEEE Trans Power Syst., Vol.2, No.25, pp.1064-77.

Chandram K., Subrahmanyam N.and Sydulu M., 2011. Equal embedded algorithm for economic load dispatch problem with transmission losses, Int J Electr Power Energy Syst, Vol.33, pp.500-507.

Chaturvedi KT., Pandit M and Srivastava L., 2008. Self-organizing hierarchical particle swarm optimization for nonconvex economic dispatch. IEEE Trans Power Syst., Vol.23, No.3, pp.1079-87.

Civicioglu Pinar., 2013. Backtracking Search Optimization Algorithm for numerical optimization problems, Applied Mathematics and Computation, Vol. 219, pp.8121-8144.

Dalvand M., Ivatloo B., Najafi A and Rabiee A., 2012. Continuous quick group search optimizer for solving non-convex economic dispatch problems. Electr Power Syst. Res., Vol.93, pp.93-105.

Deshmukh M.K.,and Deshmukh S.S.,2008, Modeling of hybrid renewable energy systems, Renewable and Sustainable Energy Reviews, Vol. 12, pp. 235-249

Dubey H M., Pandit M., Panigrahi BK and Udgir M., 2014.A fuzzified improved hybrid PSO GSA for environmental /economic power dispatch. Inter. J. Engineering, science and Technology, Vol.6, No 4, pp.11-23,.

Dubey H M., Pandit M and Panigrahi BK., 2015. Hybrid flower pollination algorithm with time-varying fuzzy selection mechanism for wind integrated multi-objective dynamic economic dispatch. Renewable Energy, Vol. 83, pp.188-202.

Dubey H M., Pandit M and Panigrahi B.K., 2015. A Biologically Inspired Modified Flower pollination Algorithm for solving Economic Load Dispatch Problems in Modern Power Systems. Cognitive Computation, DOI 10.1007/s12559-015-9324-1

Dubey H M., Panigrahi BK and Pandit M., 2014. Bio-Inspired Optimization for Economic Load Dispatch: A Review. International Journal of Bio-Inspired Computation, Vol.6, No.1, pp.7-21.

Duffie JA and Beckman WA., 1991. Solar engineering of thermal processes, 2nd ed. USA: Wiley

Duman S., Yorukeren N. and Altas I. H., 2015. A novel modified hybrid PSOGSA based on fuzzy logic for non-convex economic dispatch problem with valve-point effect . Int J Electr Power Energy Syst., Vol.64, pp.121-135.

Habib M.A., Said S.A.M, El-Hadidy MA and Al-Zaharna I., 1999. Optimization procedure of a hybrid photovoltaic wind energy system. Energy Vol.24,pp.919-29.

Hetzer J., Yu D.C and Bhattarai K., 2008. An Economic Dispatch Model Incorporating Wind Power. IEEE Trans Energy Conver., Vol.23, No.2, pp. 603-611.

Ivatloo B. Mohammadi., Rabiee A., Soroudi A. and Ehsan M., 2012 .Iteration PSO with time varying acceleration coefficients for solving non-convex economic dispatch problems. Int. J. Electr. Power Energy Syst. Vol.1,No.42, pp. 508-516.

Karaki S. H., Chedid R. B and Ramadan R., 1999. Probabilistic Performance Assessment of Autonomous Solar-Wind Energy Conversion Systems. IEEE Transactions on Energy Conversion, Vol.14, No.3, pp. 766-772 .

Mandal B., Roy P. K.., and Mandal S., 2014. Economic load dispatch using krill herd algorithm. Int J Electr Power Energy Syst, vol.57, pp.1-10.

Noman N and Iba H., 2008. Differential evolution for economic load dispatch problems. Electr Power Syst. Res., Vol.78, No.8, pp.1322-31.

Oreo S.O and Irving M.R., 1996. Economic Dispatch of Generators with Prohibited Operating Zones: A Genetic Algorithm Approach. IET Proc Gener Transm Distrib., Vol. 143, No.6, pp.529-534.

Panigrahi BK and Pandi VR., 2008. Bacterial foraging optimisation: Nelder Mead hybrid algorithm for economic load dispatch. IET Proc Gener Transm Distrib., Vol.2, No.4, pp.556-65. 
Park JB., Jeong YW., Shin JR and Lee K Y., 2010. An Improved Particle Swarm Optimization for Nonconvex Economic Dispatch Problems. IEEE Trans on Power Systems, Vol.25, No.1, pp. 156-166.

Pothiya S, Ngamroo I and Kongprawechnon W., 2010. Ant colony optimization for economic dispatch problem with non-smooth cost functions. Int J Electr Power Energy Syst., Vol.5, No.32, pp.478-87.

Reddy S. S., and Momoh J. A., .Realistic and Transparent Optimum Scheduling Strategy for Hybrid Power System. IEEE Trans on smart grid, D O I: 10.1109/TSG.2015.2406879(Article)

Reddy S. S., Panigrahi B.K.., Kundu R., Mukherjee R and Debchoudhury S., 2013. Energy and spinning reserve scheduling for a wind-thermal power system using CMA-ES with mean learning technique. Int J Electr Power Energy Syst, Vol.53, pp.113122.

Roy P.K., Bhui S., Paul C., 2014. Solution of economic load dispatch using hybrid chemical reaction optimization approach. Applied Soft Computing, Vol.24, pp.109-125.

Selvakumar A and Thanushkodi K.., 2007. A new particle swarm optimization solution to nonconvex economic dispatch problems. IEEE Trans Power Syst., Vol.22, No.1, pp.42-51.

Sinha N., Chakrabarti R and Chattopadhyay PK., 2003. Evolutionary programming techniques for economic load dispatch. IEEE Trans Evol Comput., Vol.7, No.1, pp.83-94.

Solar Radiation Hand Book (2008), A joint Project of Solar Energy Centre, MNRE Indian Metrological Department.

Udgir M., Dubey H.M. and Pandit M., 2013. Gravitational Search Algorithm: A Novel Optimization Approach for Economic Load Dispatch. Proc. of IEEE International Conference on Microelectronics, Communications and Renewable Energy (AICERA/ICMiCR:2013), 4-6 June 2013,pp.1-6.

Vishwakarma K. K., Dubey H M., Pandit M and Panigrahi BK, 2013. Simulated annealing approach for solving economic load dispatch problems with valve point loading effects. Inter. J. of Engineering, Science and Technology, Vol.4, No.4, pp. 60-72.

Walter D.C and Sheble G.B., 1993. Genetic Algorithm Solution of Economic Load Dispatch with Valve Point Loading. IEEE Trans. on Power System, Vol.8, pp.1325-1332.

Wang C. and Shahidepour S.M., 1993. Effects of ramp rate limits on unit commitment and economic dispatch. IEEE Trans. on Power System, Vol.8, No.3, pp.1341-1350.

Wood A.J and Wollenberg B.F., 1984. Power Generation Operation and Control, New York: Wiley.

Zhu Y., Wang J. and Qu B., 2014. Multi-objective economic emission dispatch considering wind power using evolutionary algorithm based on decomposition. Int J Electr Power Energy Syst, Vol.63, pp. 434-445.

\section{Biographical notes}

Nitin Tyagi obtained his B.E. degree in Electrical and Electronics Engineering from UCER, Greater Noida (India) in 2012. He is presently doing M.E. in Industrial Systems and Drives (ISD) from M.I.T.S., Gwalior, (India).

Hari Mohan Dubey obtained his M.E. degree in Electrical Engineering from Madhav Institute of Technology \& Science Gwalior (India) in 2002. He is currently working as Assistant Professor in Department of Electrical Engineering, M.I.T.S., Gwalior, (India). His areas of research are Computational intelligence algorithm and their applications to power system.

Manjaree Pandit obtained her M. Tech degree in Electrical Engineering from Maulana Azad College of Technology, Bhopal, (India) in 1989 and Ph.D. degree from Jiwaji University Gwalior (India) in 2001. She is currently working as Professor in Department of Electrical Engineering, M.I.T.S., Gwalior, (India). Her areas of interest are Power System Security Analysis, Optimization using soft computing/ evolutionary methods, ANN and Fuzzy neural applications to Power System.

Received June 2016

Accepted December 2016

Final acceptance in revised form December 2016 